\title{
O processo de construção da política de formação dos funcionários da educação
}

\section{The construction process of the policy of formation of education employees \\ El proceso de construcción de la política de formación de los funcionarios de la educación}

\author{
LEANDRO APARECIDO DE SOUZA (10 ${ }^{1}$ \\ Alberto Albuquerque GoMES ${ }^{2}{ }^{2}$ \\ ${ }^{1}$ Universidade Estadual Paulista, Birigui, SP, Brasil.
}

${ }^{2}$ Universidade Estadual Paulista, Presidente Prudente, SP, Brasil.

$\diamond$

\begin{abstract}
RESUMO
O artigo é o resultado de uma pesquisa documental de cunho qualitativo que teve como objetivo compreender o processo de criação da Política Nacional de Formação dos Profissionais da Educação Básica, além de discutir o papel do Estado em sua elaboração. O estudo, desenvolvido com elementos da abordagem do ciclo de políticas de Stephen J. Ball, permitiu identificar a atuação da sociedade civil constatando que o surgimento de uma política não está submetido somente à racionalidade estatal, mas sujeito a influências externas. A análise também evidenciou a construção de um percurso em torno de um projeto emancipatório, de atendimento a reivindicações sociais, para a formação profissional dos funcionários da educação.
\end{abstract}

Palavras-chave: Funcionários da educação. Política educacional. Profuncionário. Ciclo de políticas.

\begin{abstract}
The article is the result of a qualitative documentary research whose objective was to understand the process of creation of the National Policy for the Training of Primary Education Professionals, besides discussing the role of the State in its elaboration. The study, developed with elements of Stephen J. Ball's policy cycle approach, allowed us to identify the performance of civil society by showing that the emergence of a policy is not subject only to state rationality but subject to external influences. The analysis also evidenced the construction of a course around an emancipatory project, of attendance to social claims, for the professional formation of the education employees.
\end{abstract}

Keywords: Education employees. Educational Politics. Profuncionário. Policy cycle approach.

\section{RESUMEN}

El artículo es el resultado de una investigación documental de cuño cualitativo que tuvo como objetivo comprender el proceso de creación de la Política Nacional de Formación de los Profesionales de la Educación Básica, además de discutir el papel del Estado en su elaboración. El estudio, desarrollado con elementos del enfoque del ciclo de políticas de Stephen J. Ball, permitió identificar la actuación de la sociedad civil evidenciando que el surgimiento de una política no está sometido solamente a la racionalidad estatal, sino sujeto a influencias externas. El análisis también evidenció la construcción de un recorrido en torno a un proyecto emancipatorio, de atención a reivindicaciones sociales, para la formación profesional de los funcionarios de la educación.

Palabras clave: Funcionarios de la educación. Política educativa. Profuncionário. Ciclo de políticas. 


\section{INTRODUÇÃO}

Em 2010, por meio do Decreto no 7.415 (BRASIL, 2010), foi instituída a Política de Formação dos Profissionais da Educação Básica, estabelecendo a formação dos funcionários da educação. Esses profissionais são responsáveis pela limpeza dos ambientes escolares, preparação das refeições, secretarias, bibliotecas, portões, organização, ou seja, são as faxineiras, as merendeiras, os secretários, os auxiliares administrativos, os bibliotecários, os vigias, os porteiros, os inspetores, os motoristas etc.

A discussão sobre a necessidade de sua formação ganhou o cenário nacional em 2004, por meio do Seminário Nacional de Valorização dos Trabalhadores em Educação (BRASIL, 2004), realizado pelo Ministério da Educação (MEC). As reflexões realizadas identificaram que a escola atual não somente ensina, mas educa. Seus espaços, para além das salas de aulas, são considerados educativos e os funcionários que ali desempenham as suas atividades são também educadores. Os professores continuam como figuras centrais do processo de ensino e aprendizagem, mas passam a contar com a atuação dos funcionários no processo educativo dos alunos.

A política em questão efetiva antigas reivindicações dos funcionários da educação na busca de reconhecimento, formação profissional e construção de sua identidade profissional. Neste sentido, considerando as transformações recentes no cenário educacional, empregadas pela inclusão dos funcionários nos programas de formação do governo federal, o questionamento deste artigo passa a ser: como foi criada a Política de Formação dos Profissionais da Educação Básica?

Para Vieira (2007) o surgimento de uma política não ocorre unicamente de dentro do aparelho do Estado, como se não sofresse influências da sociedade civil, pelo contrário, trata-se de um processo complexo. Para a autora, o advento de uma política não está submetido somente à racionalidade estatal, mas sujeito a disputas e jogos de poder, entre o Estado e a sociedade civil. Sendo assim, buscando analisar os elementos relacionados à construção de uma política pública, o objetivo deste artigo é compreender o processo de criação da Política de Formação dos Profissionais da Educação Básica.

Para a análise da política utilizamos elementos presentes na "abordagem do ciclo de políticas" (policy cycle approach), de Stephen J. Ball, que em sua formulação atual considera cinco contextos: o de influência, o da produção de texto, o da prática, o dos resultados/efeitos e o de estratégia política. Para este estudo abordaremos os dois primeiros contextos - o de influência e o da produção de textos (MAINARDES, 2006). Outrossim, com o propósito de dar mais profundidade ao nosso estudo, e considerando a advertência de Afonso (2005), sobre a importância de se considerar o aparelho estatal nos estudos de políticas, incluímos em nossas análises o papel exercido pelo Estado na criação da política de formação dos funcionários da educação.

\section{AS “QUESTÕES DE FUNDO" DA POLÍTICA DE FORMAÇÃO (CONTEXTO DE INFLUÊNCIA)}

Iniciamos a análise da Política Nacional de Formação dos Profissionais da Educação Básica abordando o contexto de influência (MAINARDES, 2006), ou, como denomina Höfling (2001), com as "questões de fundo" da política, na busca de identificar o local ou as questões relacionadas ao seu surgimento. Realizamos primeiramente um recorte temporal mais amplo, porém não exaustivo, sobre a situação política do país, considerando as mudanças em sua história recente.

A década de 1980 foi para o Brasil um período de redemocratização com o fim da ditatura militar. $\mathrm{Na}$ década posterior o Estado brasileiro passou por uma série de reformas sociais, políticas e econômicas de cunho neoliberal, dando início às construções de parcerias entre o Estado e a sociedade civil. As políticas educacionais na década de 1990 foram implementadas através de um conjunto articulado de reformas, com orientações de organismos internacionais e um viés mercantilizador da educação nacional (SHIROMA; MORAES; EVANGELISTA, 1999).

Essa tendência mercantilizadora da política e da educação, se comparada ao cenário internacional, foi estruturada posteriormente no Brasil, sendo implantada na década de 1990, na gestão do governo do Presidente Fernando Henrique Cardoso e do Ministro da Educação, Paulo Renato Souza. No Reino Unido, por exemplo, foi na década de 1980 que se iniciou a disseminação das discussões sobre as formas de organização e provisão social, principalmente no setor público, uma abordagem em que as pessoas eram conduzidas a incorporar os princípios mercadológicos e gerenciais (BALL, 2011).

No início da década de 2000 o País passou por significativas mudanças políticas. Em 2003, após duas sucessivas administrações, em que o presidente era filiado ao Partido da Social Democracia Brasileira (PSDB), assumiu a presidência Luiz Inácio Lula da Silva, popularmente conhecido como Lula, fundador do Partido dos Trabalhadores (PT), permanecendo no comando do País por dois mandatos. Após a sua saída, foi eleita como presidente Dilma Vana Roussef, reeleita em 2014, mas destituída do poder em agosto de 2016 (BRASIL, 2017).

Se a década de 1990 foi marcada por características neoliberais aplicadas à educação, no período que se 
seguiu houve o seu reposicionamento estratégico. Gentili e Stubrin (2013) ao analisarem o período de 2003 a 2013 no Brasil, identificam quatro evidências de uma década de conquistas democráticas: direito à educação e mais justiça social; investimento e maior compromisso público; maior participação; e mais universidades e maior desenvolvimento social. Os autores evidenciam esse avanço democrático a partir dos valores investidos durante uma década na educação - aumento do investimento advindo do produto interno bruto na educação, de $4,8 \%$, em 2002, para $6,1 \%$, em 2011. Além dos dados quantitativos dos investimentos, para eles também foi destaque do período a participação popular e sua intervenção na política educacional (sindicatos docentes, movimento negro, movimentos do campo e indígenas).

Esses foram, em um panorama mais amplo, os acontecimentos que marcaram as últimas décadas no País e que estavam postos como pano de fundo para as ações no campo educacional que exploraremos a seguir.

\section{A INCLUSÃo doS FUNCIONÁRIOS DA EDUCAÇÃO NA AGENDA NACIONAL}

Em 2004, entre os dias 26 e 28 abril, foi realizado pela Secretaria de Educação Básica (SEB) do MEC, por meio do Departamento de Articulação e Desenvolvimento dos Sistemas de Ensino (Dase), o Seminário Nacional sobre Política de Valorização de Trabalhadores em Educação, incluindo na agenda nacional a discussão sobre a valorização dos funcionários da educação. $\mathrm{O}$ documento elaborado em decorrência do evento apresenta as atividades desenvolvidas, a proposta para debate sobre a política de valorização e os pressupostos básicos para o delineamento da política de valorização. Assevera a necessidade de uma nova concepção de educação, responsável em fortalecer a cidadania e enfrentar problemas como a crise ética, o aumento da violência e a discriminação social (BRASIL, 2004).

Estavam presentes no evento para subsidiar a discussão inicial entidades gestoras e organizações de classe, representantes dos sindicatos dos estados e do Distrito Federal, das Secretarias Estaduais de Educação (SEE) e Distrito Federal, de 26 capitais, da SEB, da Secretaria de Educação Profissional e Tecnológica (Setec), do Instituto Nacional de Estudos e Pesquisas Educacionais Anísio Teixeira (Inep), do Conselho Nacional de Educação (CNE), do Conselho Nacional de Secretários de Educação (Consed), da União Nacional dos Dirigentes Municipais de Ensino (Undime), Confederação Nacional dos Trabalhadores em Educação (CNTE), palestrantes, representantes de agências de formação e representantes de vários estados com mais de 40 mil alunos na educação básica, dando um caráter plural no evento.
As identidades funcionais passaram a ser reconfiguradas, ampliaram suas responsabilidades - as merendeiras, além de prepararem as refeições, precisam cuidar da educação alimentar dos alunos; as bibliotecárias precisam colaborar na construção do hábito da leitura e da educação literária; e os secretários e auxiliares administrativos devem colaborar com o processo avaliativo do ensino e da aprendizagem etc.

O Seminário foi realizado em três momentos, o primeiro de aprofundamento teórico, desde a discussão e apresentação dos aspectos e proposições legais até a formação profissional para a categoria. No segundo momento houve a discussão sobre os relatos de experiências formativas dos funcionários, com ênfase para as ações que vinham sendo desenvolvidas no estado de Mato Grosso que, tanto pela experiência, organização e sistematicidade da formação, quanto pelo reconhecimento legal dos funcionários, subsidiaram o Seminário. Por último, houve a organização dos participantes em grupos de trabalho para a elaboração do documento referencial para a formulação da política.

No corpo do documento, além dessas informações, podemos encontrar elementos e características que contribuem com a identificação do tipo de Estado presente no processo de formulação da política que iremos analisar. Uma delas relaciona-se à responsabilidade assumida pelo governo no posicionamento da educação enquanto elemento estratégico de desenvolvimento nacional:

A decisão de transformar a educação em elementochave, fator estratégico de desenvolvimento nacional com inclusão social, assumida pelo presidente, já está demonstrando, na prática, que a revolução educacional está em curso e não será interrompida (BRASIL, 2004, p. 8).

Outra característica relaciona-se à forma de atuação do Estado, pois além de atender a antigas reivindicações dos funcionários, demonstra um caráter democrático e participativo em sua gestão. Opera em conjunto na discussão sobre a necessidade de valorização dos trabalhadores em educação, permitindo a participação de diferentes órgãos e entidades, ou seja, a contribuição de várias vozes (CNTE, Undime e Consed).

O Estado, representado nas ações do MEC, posiciona-se atento às necessidades de formação de todos os envolvidos no processo educativo, criticando de certa forma as gestões anteriores, buscando agir de forma diferente $\mathrm{e}$ atento às necessidades $\mathrm{e}$ às demandas sociais:

Entretanto, a negação do direito alheio não encontra amparo em uma gestão educacional ética e democrática, que atribui a importância devida a cada agente do processo educativo. A reivindicação da sociedade brasileira por uma escola pública que ofereça as 
necessárias condições para o acesso e a permanência do educando, incluindo-se aí justas e solidárias relações de trabalho, ganha alento na intenção do MEC de promover, implementar e consolidar uma política de valorização para os profissionais da educação básica (BRASIL, 2004, p. 44).

Com essas reflexões introduzimos elementos que nos ajudarão a identificar a concepção de Estado que pautou a elaboração da Política Nacional de Formação dos Profissionais da Educação Básica. No entanto, antes de analisar o papel do Estado, explicitaremos as ações que vinham sendo desenvolvidas no estado de Mato Grosso, a fim de elucidar o seu contexto e compreender o porquê de elas serem subsidiárias às discussões no Seminário.

\section{Ações no estado de Mato Grosso}

Nos últimos anos da década de 1980 a Associação Mato-grossense de Professores (AMP) estendeu a filiação aos funcionários das escolas e se transformou na Associação Mato-grossense de Profissionais da Educação (Ampe). Foi a precursora no processo de unificação das categorias em um único sindicato. Pouco tempo depois, a Ampe se converteu em Sindicato dos Trabalhadores no Ensino Público de Mato Grosso (Sintep-MT) (SINDICATO DOS TRABALHADORES NO ENSINO PÚBLICO DE MATO GROSSO, 2016).

Monlevade, que integrou naquele mesmo período a equipe responsável pela elaboração da Lei de Gestão Democrática da Rede Estadual de Mato Grosso, elucida que ao elaborarem o texto tiveram o cuidado de compor o Conselho Deliberativo Escolar não somente com pais, alunos e professores, mas também com os funcionários da educação. Optaram em separar os professores da categoria dos funcionários para que essa não ficasse subsumida àquela (MONLEVADE, 2001, p. 42).

$\mathrm{O}$ texto aprovado deu origem à Lei $\mathrm{n}^{\mathrm{o}} 5.604$, de 22 de maio de 1990, de Mato Grosso, estabelecendo que os funcionários da educação integrassem os conselhos escolares - "com representação eleita e paritária dos quatro segmentos da comunidade escolar: alunos, pais, professores e funcionários, e presença nata da direção eleita (MATO GROSSO, 1990, p. 2, grifo nosso).

Embora a participação dos funcionários nos conselhos contribuísse para a legitimação da gestão democrática, através da representação eleita e paritária, eles faziam parte do quorum, mas, ao invés de atuarem nas deliberações, apenas concordavam com a posição da maioria. Esse cenário revelava sérios problemas relacionados à formação cultural, à ausência de escolarização e de profissionalização, além de secundarizar o papel dos funcionários da educação, tanto na escola, quanto na sua gestão (MONLEVADE, 2001).
Ainda que a questão da profissionalização dos funcionários da educação fosse discutida desde a Ampe, o projeto piloto para sua profissionalização foi idealizado pelo Sintep-MT, por meio de quatro diferentes tipos de cursos técnicos: Técnico em Administração Escolar; Técnico em Multimeios Didáticos; Técnico em Alimentação Escolar; e Técnico em Manutenção de Infraestruturas Escolares.

Para reforçar o caráter de profissionais da educação, em 1994, ao aprovar a Lei no 3.330 (CUIABÁ, 1994), que dispôs sobre a organização do magistério público municipal, o município de Cuiabá reconheceu como grupo ocupacional do magistério além dos professores, os técnicos em administração escolar básica formados em uma das quatro modalidades de cursos preconizadas pelo Sintep-MT. Ainda que em 2004 essa lei tenha sido revogada pela Lei no 4.594 (CUIABÁ, 2004), não houve retrocessos em relação ao reconhecimento profissional dos funcionários da educação. A Lei Complementar $n^{0}$ 50, de 1 de outubro de 1998, do estado de Mato Grosso (1998), assim como estabelecia a lei anteriormente citada, do Município de Cuiabá, descreveu os profissionais da educação básica e reconheceu o caráter de profissional dos cursos técnicos.

Por meio das informações apresentadas é possível verificar que o Município de Cuiabá e o estado de Mato Grosso iniciaram o processo de construção da identidade, reconhecimento e formação profissional dos funcionários da educação na década de 1990. Enquanto a legitimação e o reconhecimento nacional desses trabalhadores começaram a ser efetivados em meados da década de 2000, o Município de Cuiabá o fez em 1994 e o estado de Mato Grosso em 1998.

Até o momento buscamos abordar as influências e tendências presentes no contexto em que a política investigada emergiu. Identificamos como elementos subsidiários para as discussões no Seminário as ações desenvolvidas, principalmente, no estado de Mato Grosso, tanto em relação ao reconhecimento pelos instrumentos normativos, quanto à experiência, organização e sistematicidade da formação profissional dos funcionários da educação.

O Seminário de 2004 inseriu na agenda nacional a discussão sobre a participação dos funcionários na formação dos alunos, ressignificando o espaço escolar e estabelecendo a formação profissional como pressuposto básico para a valorização do trabalhador em educação. Apresentou conceitos sobre educação (e suas finalidades), ética, cidadania, habilidades, colaboração e interação, construindo a base do discurso político. A seguir abordaremos como se processou a materialização desses elementos nos textos políticos formais. 


\section{CONSTRUÇÃo dOS TEXTOS POLÍTICOS (CONTEXTO DA PRODUÇÃo DE TEXTO)}

Em 31 de maio de 2007, o Ministro da Educação, Fernando Haddad, por meio da Portaria Normativa $n^{0}$ 25 (BRASIL, 2007a) instituiu o Programa de Formação Inicial em Serviço dos Profissionais da Educação Básica dos Sistemas de Ensino Público - Profuncionário e estabeleceu o seu conselho político, através da Portaria no 539 (BRASIL, 2007b).

O primeiro documento instituiu o Profuncionário, enquanto programa de formação inicial, por meio da educação a distância, para os funcionários em exercício nos sistemas de ensino da educação básica pública, com ensino médio concluído ou concomitante, em quatro modalidades: Gestão Escolar; Alimentação Escolar; Multimeios Didáticos; e Meio Ambiente e Manutenção da Infraestrutura Escolar. Também foi estabelecido que o seu gerenciamento deveria ser efetuado pela SEB, por meio do Dase, através da designação de uma coordenação geral para o programa. Designou-se que a implementação seria feita em parceria com a União, estados, municípios e Distrito Federal, formalizada por meio de acordo de cooperação técnica, no qual cada esfera deveria estabelecer uma coordenação estadual para implementação e gestão do curso, tendo como membros representantes dos seguintes órgãos e entidades: SEE; Undime/Estadual; Conselho Estadual de Educação (CEE); e Sindicatos filiados à CNTE.

Neste primeiro momento, em que o Profuncionário foi instituído como programa de formação, não houve destinação orçamentária específica, ou seja, não houve suplementação de verba para a execução do programa, forçando os entes interessados a ajustarem os seus orçamentos para oferecerem os cursos.

O conselho político do Profuncionário foi estabelecido pelo segundo documento. Sua composição incluiu representantes de diferentes esferas: SEE, Secretaria de Educação a Distância (SEED), Setec, Consed, Undime, Fórum Nacional dos Conselhos Estaduais de Educação e CNTE, sob a presidência do primeiro órgão por meio do Dase.

Em setembro de 2008 duas portarias foram emitidas pelo MEC. A primeira, Portaria no 13 (BRASIL, 2008b), estabeleceu que o Profuncionário fosse gerenciado pela Diretoria de Políticas de Formação, Materiais didáticos e de Tecnologias para a Educação Básica e que as Instituições de Ensino Superior credenciadas fossem responsáveis pelas atividades de formação e desenvolvimento pedagógico do curso, mediante uma coordenação pedagógica. A segunda portaria, de $\mathrm{n}^{\mathrm{o}}$ 1.199 (BRASIL, 2008a) incluiu como membro no Conselho Político do Profuncionário um representante do Conselho de Dirigentes dos Centros Federais de Educação Tecnológica (Concefet) e estabeleceu que a sua presidência ficaria a cargo da diretoria de gerenciamento, citada acima.

Esses documentos foram responsáveis por criar o programa de formação dos funcionários da educação, as suas diretrizes e estabelecer o seu conselho gestor, mas não a política. Ela viria a ser criada seis anos após o início das discussões em âmbito nacional, em 30 de dezembro de 2010, por meio do Decreto no 7.415 (BRASIL, 2010), que instituiu a Política Nacional de Formação dos Profissionais da Educação Básica e dispôs sobre o Profuncionário ${ }^{1}$. O decreto estabeleceu tanto os princípios, quanto os objetivos da Política Nacional de Formação dos Profissionais da Educação Básica, formalizando as responsabilidades com a educação assumidas pelo governo.

Podemos perceber que a política, representando as ações do Estado, legitima não somente o discurso iniciado durante o Seminário de 2004, ao reconhecer a participação dos funcionários da educação no processo educativo dos alunos, como também reconhece que a educação não se restringe à sala de aula, considerando as potencialidades educativas dos demais ambientes escolares. Isto é, qualifica como educativo os momentos em que os alunos estão sendo assistidos pelos demais profissionais da educação, que não os professores, durante as refeições, na entrada e saída, nos intervalos, nas secretarias etc.

A União, por meio do MEC, estabeleceu o apoio às ações de formação inicial e continuada dos profissionais da educação básica ampliando a oferta de vagas em cursos pela Rede Federal de Educação Profissional e Tecnológica, e a concessão de bolsas de pesquisa e estudo aos professores que atuassem nos cursos para os funcionários da educação.

Uma das principais ações do decreto foi fomentar o acesso à formação inicial dos funcionários da educação por meio do Profuncionário. As orientações do documento seguiram as especificações da Portaria do MEC no 25 (BRASIL, 2007a), sobre a realização no formato de educação a distância, no entanto, foram incluídas duas novas habilitações, Técnico em Biblioteconomia e Técnico em Orientação Comunitária. Nesta questão, podemos perceber que as habilitações apresentadas no Seminário de 2004, originárias das experiências de formação do estado de Mato Grosso, explicitando as reivindicações das necessidades identificadas naquele momento pelos participantes, foram atendidas na materialização da política. Mais que isso, ainda houve uma complementação,

\footnotetext{
${ }^{1}$ O contexto desse decreto demanda uma observação. Em 2009, foi aprovada a Lei no 12.014 (BRASIL, 2009) que discrimina as categorias de profissionais da educação, estabelecendo três grupos: os professores, os pedagogos e os funcionários da educação.
} 
ao incluírem duas outras habilitações. Coadunando o caráter participativo e democrático presente no momento inicial de discussão da política, os órgãos gerenciadores permaneceram os mesmos.

\section{Produção TeXtual SECUNDÁria - ORIENTAÇÕES E ALTERAÇÕES}

No mesmo ano em que o Profuncionário foi instituído como Programa de Formação Inicial em Serviço dos Profissionais da Educação Básica (BRASIL, 2007a), houve a produção de um documento subsidiário pelo MEC. O texto intitulado de "Orientações Gerais", teve o objetivo de apresentar a proposta político-pedagógica aos envolvidos - alunos, professores orientadores, tutores, coordenação etc. (BRASIL, 2007c). Atualmente o caderno de orientações encontra-se na quarta edição (BRASIL, 2012).

Além dessa produção houve, ainda relacionada ao contexto da produção de texto, uma alteração significativa no texto principal da política. O Decreto no 8.752 de 9 de maio de 2016 (BRASIL, 2016a), passou a dispor sobre a Política Nacional de Formação dos Profissionais da Educação, unificando em um documento a política de formação dos professores e dos funcionários, em consonância com as Metas 15 e 16 do Plano Nacional de Educação (BRASIL, 2014), e com os planos decenais dos municípios, estados e Distrito Federal. Sua publicação revogou dois dispositivos, o Decreto $\mathrm{n}$ - 6.755, que havia instituído a política de formação para os profissionais do magistério, e o Decreto no 7.415 , que tratava da formação dos funcionários da educação.

O documento estabelece os princípios, os objetivos da política e como deve se organizar seus programas e ações. Percebemos a existência de um encadeamento dos princípios presentes no texto político em vigor, em relação à norma anterior (Decreto $\mathrm{n}$ - 7.415), tais como: $\mathrm{o}$ compromisso com o projeto social, político e ético, que contribua não só com o desenvolvimento da nação, mas que promova a emancipação dos indivíduos e grupos sociais; a articulação entre teoria e prática, fundada nos conhecimentos científicos, pedagógicos e técnicos; a compreensão dos profissionais da educação como agentes do processo educativo, sendo necessária a sua permanente formação para que possam contribuir com a melhoria da qualidade da educação básica e com a qualificação do ambiente escolar; a sua valorização etc.

A idealização de aporte com a qualidade da educação que está presente desde o Seminário de 2004, ao reconhecer as contribuições que os funcionários podem imprimir à educação, tem sido mantida ao longo dos textos. Assim como o de uma nova concepção de educação, ou seja, a escola deixa de ser uma instituição voltada exclusivamente ao ensino para se tornar agência comprometida com a construção de valores democráticos e cidadãos.

No que se relaciona à organização da política, o documento apresenta algumas novidades estruturais. Fica a cargo do MEC a proposição de um documento de referência, o Planejamento Estratégico Nacional, responsável em orientar a formulação do Plano Estratégico de cada ente federado, e também pela implementação das ações e programas integrados e complementares (apoio técnico e financeiro aos partícipes), dando sustentação à política nacional.

É possível notar uma concentração sobre questões de concepção e regulação da política no nível federal, pois os entes federados deverão seguir as orientações e atribuições estabelecidas pelo MEC, o que pode incorrer em novas relações internas na gestão da política, uma vez que se altera a organização anterior, que esteve presente desde a realização do Seminário em 2004.

No texto vigente da política, embora sejam tratadas as três categorias de profissionais da educação, percebemos que há uma ênfase das ações relacionadas à formação inicial e continuada para os professores. Os funcionários da educação são destacados mais especificamente em dois momentos, na alínea V do Art. 11 e na alínea I do Art. 12.

O parágrafo único do Art. 18 estabelece que os "planos estratégicos estadual e distrital de formação em andamento e aos outros programas e ações de formação de profissionais da educação em execução continuam em vigência até seu encerramento" (BRASIL, 2016a, p. 6) até que novos entrem em vigor, o que pode ser compreendido como a continuidade do Profuncionário. Partindo desse pressuposto, a Portaria $\mathrm{n}$ - 25 , de 31 de maio de 2007 (BRASIL, 2007a), e as demais que se sucederam (BRASIL, 2007b; 2008a; 2008b) continuam em vigor e passam a ser as normas de referência e orientações ao programa.

Ainda que tenha havido mudanças no instrumento legislativo da Política Nacional de Formação dos Profissionais da Educação Básica, por meio da unificação dos decretos, os conceitos principais - contribuição dos profissionais da educação para a qualidade da educação básica; compreensão de qualidade da educação como apropriação da cultura, valores e conhecimentos; formação inicial e continuada; a profissionalização como instrumento de valorização; e a qualificação dos espaços escolares - continuam presentes. Embora tenhamos identificado alguma centralidade de regulação e poder no MEC, e consequentemente uma alteração nas vozes ouvidas, dada por essa última alteração, ainda assim, o caráter participativo permanece.

Apesar da predominância de ações para o magistério, o Decreto $\mathrm{n}^{\mathrm{O}} 8.752$ garante a realização de programas e 
ações integrados e complementares voltados à formação em nível médio e superior ${ }^{2}$ para os funcionários da educação. Considerando o primeiro texto da política, Decreto $\mathrm{n}$ - 7.415, e os seus elementos em relação aos funcionários da educação, parece-nos que seria mais favorável um instrumento único, que zelasse pelas especificidades próprias da categoria. Todavia, efetivando-se aquilo que é preconizado no decreto vigente, o futuro da categoria aparenta ser alvissareiro.

\section{O PAPEL Do ESTAdo}

Burton (2014) afirma que embora as mudanças vivenciadas pelo papel do Estado nas últimas décadas enfatizem a influência de ação do mercado e de fornecedores da iniciativa privada no campo de estudo das políticas públicas, houve um certo negligenciamento da influência de outros atores na formulação de políticas educacionais, que têm agido em conjunto com interferências sociais e econômicas, em um sistema menos estático e mais globalizado. Essa concepção estaria, então, relacionada à uma visão neopluralista do Estado.

Por conseguinte, analisando as discussões e concepções do Seminário de 2004 com o texto do primeiro decreto (Decreto no 7.415), que instituiu a Política Nacional de Formação dos Profissionais da Educação Básica e que materializa a política de valorização dos funcionários da educação, podemos identificar que as prerrogativas e as concepções instauradas naquele momento inicial foram mantidas (centralidade da educação e carácter participativo na elaboração e gestão da política). Os órgãos e entidades que estiveram presentes enquanto os discursos e os conceitos da política estavam sendo disseminados também tiveram a sua participação legitimada nos instrumentos normativos.

As ações realizadas no estado de Mato Grosso, iniciadas pelo sindicato dos funcionários sobre a necessidade de sua formação, que alicerçaram as discussões no Seminário de 2004, indicam que os movimentos de criação das políticas não são iniciativas que surgem unicamente de dentro do aparelho do Estado. Neste caso específico, a sociedade civil teve participação ativa durante o processo, evidenciando que o surgimento de uma política não está submetido somente à racionalidade estatal e que a escola se estabelece como espaço "vivo" e participativo, contribuindo com a sua formulação (VIEIRA, 2007).

A demanda identificada pelas ações no estado de Mato Grosso voltadas à profissionalização e ao reconhecimento pelos instrumentos normativos dos funcionários da

\footnotetext{
2 A Resolução no 2, do CNE, da Câmara de Educação Superior (BRASIL, 2016b), estabelece as DCN para a formação inicial e continuada em nível superior para os funcionários da educação básica.
}

educação serviram de subsídio para a discussão da questão no cenário nacional, conforme consta nos textos criados a partir do Seminário. Não identificamos nos documentos consultados o atendimento a uma agenda internacional, de recomendação de organismos multilaterais, mas a uma solicitação advinda de um órgão representativo de classe - Ampe -, em um movimento "de baixo para cima". Nesse caso específico o Estado atuou de forma a atender uma reivindicação popular, ao menos na forma da lei.

Outro elemento que corrobora a identificação do papel do Estado relaciona-se à presença de outros grupos, que não somente aqueles pertencentes à estrutura do Estado, na formulação da política. Por exemplo, durante o contexto de influência, além de representantes de entidades gestoras (SEB, Setec etc.), também estiveram presentes representantes de organizações de classe (sindicatos e CNTE). Esse cenário sinaliza o caráter plural do processo possibilitando a participação das diferentes vozes, evidenciando um sistema complexo na elaboração da política.

As intervenções estatais representadas por meio dos textos políticos fornecem subsídios que nos permitem identificar quais foram os conceitos norteadores das estratégias utilizadas para o desenvolvimento das ações, bem como a qual concepção pode ser compreendida a atuação do Estado. Dessa forma, os elementos apontados no decorrer da abordagem dos contextos de influência e da produção de texto em congruência com as reflexões apresentadas por Burton (2014), permitemnos identificar o Estado, ao menos na elaboração dessa política em particular, como pertencente à concepção neopluralista.

Embora as mudanças sofridas pelo Estado nos últimos anos indiquem uma predominância de ação do mercado no campo das políticas públicas ela não é plena. De acordo com Burton (2014) o Estado não teve completa redução no seu papel e no seu tamanho, tanto quanto de outros grupos na formulação de políticas, conforme identificamos.

\section{CONSIDERAÇõ ES FINAIS}

A discussão introduzida no cenário nacional sobre a valorização dos funcionários da educação considera a escola e seus ambientes como espaços educativos. A educação como a principal função social da escola engloba a aquisição de valores e habilidades, em uma prática de trabalho coletiva e participativa, em que se faz necessária a formação profissional dos funcionários da educação para atuarem em conjunto com os professores.

A análise da Política Nacional de Formação dos Funcionários da Educação Básica, por meio do ciclo de 
políticas de Stephen J. Ball, permitiu-nos identificar que as ações que estavam sendo desenvolvidas no estado de Mato Grosso foram subsidiárias para as discussões iniciais da política nacional de formação dos funcionários da educação. O surgimento e reconhecimento de uma demanda regional, organizada e desenvolvida inicialmente por uma entidade representativa dos interesses dos funcionários (sindicato), que posteriormente contribuiu e serviu de referência para a discussão de uma política nacional, permite depreender que nem todas as políticas surgem de "cima para baixo". Além disso, identificamos que o momento histórico e o contexto político em que as reivindicações dos funcionários da educação foram atendidas compreendeu um período de transição política, em que uma nova gestão tinha assumido o comando do País.

No texto principal da política buscamos identificar elementos que fossem convergentes ou divergentes em relação ao contexto de influência, ou seja, em relação aos discursos e aos atores que estiveram presentes desde a discussão inicial da política durante o Seminário de 2004. O caminho trilhado para a compreensão e a análise da política permitiu identificar nas ações desenvolvidas no âmbito do Estado, além da atuação de grupos exógenos à estrutura estatal, a formação de um percurso em torno de um projeto emancipatório para o funcionário da educação, na medida em que o valoriza por meio do reconhecimento, de sua formação profissional e da construção de sua identidade profissional. Ademais, a trajetória desta pesquisa não evidenciou contradições em relação à política de formação, na realidade, foi possível identificar a existência de um encadeamento e de uma permanência dos princípios norteadores da política, presentes desde as primeiras discussões no Seminário de 2004 até os últimos textos normativos, conforme explicitamos anteriormente.

Assim, à guisa de conclusão, nossa concepção em relação à Política Nacional de Formação dos Profissionais da Educação Básica é positiva, pois entendemos ser essa uma medida favorável à valorização e à constituição da identidade profissional dos funcionários da educação. Com a sua inclusão na ação educativa, por meio da legitimação pelas instâncias normativas, a educação deixa de ser setorizada, limitada à atuação do professor dentro da sala de aula. A escola passa a ser compreendida como um espaço educativo e a integração entre todos os sujeitos presentes nesse processo um elemento capaz de contribuir para uma educação de qualidade.

\section{REFERÊNCIAS}

AFONSO, A. J. Avaliação educacional: regulação e emancipação para uma sociologia das políticas avaliativas contemporâneas. 3. ed. São Paulo: Cortez, 2005.
BALL, S. J. Sociologia das políticas educacionais e pesquisa crítico-social: uma revisão pessoal das políticas educacionais e da pesquisa em política educacional. In: BALL, S. J.; MAINARDES, J. (org.). Políticas educacionais: questões e dilemas. São Paulo: Cortez, 2011. p. 21-53. https://doi. org/10.7867/1809-0354.2014v9n2p392-416

BRASIL. Biblioteca da Presidência da República. Expresidentes. Brasília: Biblioteca da Presidência da República, 2018. Disponível em: http://www.biblioteca.presidencia. gov.br/presidencia/ex-presidentes. Acesso em: 31 jan. 2017. https://doi.org/10.18227/1983-9065ex.v5i1.1451

BRASIL. Decreto $\mathrm{n}^{\circ}$ 7.415, de 30 de dezembro de 2010. Institui a política nacional de formação dos profissionais da educação básica, dispõe sobre o programa de formação inicial em serviço dos profissionais da educação básica dos sistemas de ensino público - profuncionário, e dá outras providências. Diário Oficial da União, Brasília, n. 251, seção 1, 31 dez. 2010. Disponível em: http://pesquisa.in.gov.br/imprensa/jsp/ visualiza/index.jsp?jornal=1\&pagina $=11 \&$ data $=31 / 12 / 2010$. Acesso em: 14 maio 2015. https://doi.org/10.26571/23186674.a2016.v4.n2.p6-22.i5323

BRASIL. Decreto ${ }^{\circ}$ 8.752, de 9 de maio de 2016. Dispõe sobre a política nacional de formação dos profissionais da educação básica. Diário Oficial da União, Brasília, n. 88, seção 1, 9 maio 2016a. Disponível em: http://pesquisa.in.gov. br/imprensa/jsp/visualiza/index.jsp?data $=10 / 05 / 2016 \&$ jornal= 1\&pagina=5\&totalArquivos=160. Acesso em: 12 maio 2016 . https://doi.org/10.21680/1981-1802.2016v54n41id10167

BRASIL. Lei n ${ }^{\circ} 12.014$, de 6 de agosto de 2009. Altera o art. 61 da Lei no 9.394, de 20 de dezembro de 1996, com a finalidade de discriminar as categorias de trabalhadores que se devem considerar profissionais da educação. Diário Oficial da União, Brasília, n. 150, seção 1, 7 ago. 2009. Disponível em: http://pesquisa.in.gov.br/imprensa/jsp/ visualiza/index.jsp?jornal $=1 \&$ pagina $=1 \&$ data $=07 / 08 / 2009$. Acesso em: 14 maio 2015. https://doi.org/10.7867/18090354.2019v14n2p332-358

BRASIL. Lei no 13.005, de 24 junho de 2014. Aprova o Plano Nacional de Educação - PNE e dá outras providências. Brasília: Presidência da república, 2014. Disponível em: http://www.planalto.gov.br/ccivil_03/_ato2011-2014/2014/ lei/113005.htm. Acesso em: 17 fev. 2017. https://doi. org/10.1590/1413-81232014198.06322014

BRASIL. Ministério da Educação. Portaria no 13, de 25 de setembro de 2008. Altera dispositivos da Portaria Normativa no 25 , de 31 de maio de 2007. Diário Oficial da União, Brasília, n. 187, seção 1, 26 set. 2008b. Disponível em: http://pesquisa.in.gov.br/imprensa/jsp/visualiza/index. jsp?jornal=1\&pagina=13\&data=26/09/2008. Acesso em: 27 ago. 2015. https://doi.org/10.22420/rde.v11i20.774

BRASIL. Ministério da Educação. Portaria no 25, de 31 de maio de 2007. Institui o Programa de Formação Inicial em Serviço dos Profissionais da Educação Básica dos Sistemas de Ensino Público - PRO-FUNCIONÁRIO, e dá outras providências. Diário Oficial da União, Brasília, n. 105, 
seção 1, 1 jun. 2007a. Disponível em: http://portal.mec.gov. br/seb/arquivos/pdf/2008/profunc_port25.pdf. Acesso em: 14 maio 2015. https://doi.org/10.26571/2318-6674.a2016.v4.n2. p6-22.15323

BRASIL. Ministério da Educação. Portaria no 539, de 31 de maio de 2007. Institui o Conselho Político do Programa de Formação Inicial em Serviço dos Profissionais da Educação Básica dos Sistemas de Ensino Público PROFUNCIONÁRIO, e dá outras providências. Diário Oficial da União, Brasília, n. 105, seção 1, 1 jun. 2007 b. Disponível em: http://pesquisa.in.gov.br/imprensa/jsp/ visualiza/index.jsp?.jornal=1\&pagina $=12 \&$ data $=01 / 06 / 2007$. Acesso em: 14 maio 2015. https://doi.org/10.26571/23186674.a2016.v4.n2.p6-22.i5323

BRASIL. Ministério da Educação. Portaria no 1.199, de 25 de setembro de 2008. Altera dispositivos da Portaria no 539 , de 31 de maio de 2007. Diário Oficial da União, Brasília, n. 187, seção 1, 26 set. 2008a. Disponível em: http://pesquisa. in.gov.br/imprensa/jsp/visualiza/index.jsp?.jornal=1\&pagina= $14 \&$ data=26/09/2008. Acesso em: 27 ago. 2015. https://doi. org/10.22420/rde.v11i20.774

BRASIL. Ministério da Educação. Conselho Nacional de Educação. Câmara de Educação Superior. Resolução no 2, de 13 maio de 2016. Define as diretrizes curriculares nacionais para a formação inicial e continuada em nível superior para funcionários da educação básica. Brasília: MEC, 2016b. Disponível em: http://portal.mec.gov.br/index. php?option $=$ com_docman\&view $=$ download \&alias $=41081$ rces002-16-pdf\&category_slug=maio-2016-pdf\&Itemid= 30192. Acesso em: 12 dez. 2016. https://doi.org/10.21573/ vol32n012016.65704

BRASIL. Ministério da Educação. Secretaria de Educação Básica. Orientações Gerais/elaboração: Dase/SEB/MEC e CEAD/FE/UnB. Brasília: UnB, 2007c. https://doi.org/ 10.17143/ciaed/xxiiciaed.2016.00173

BRASIL. Ministério da Educação. Secretaria de Educação Profissional e Tecnológica. Orientações Gerais. 4. ed. atual. rev. Cuiabá: UFMT, 2012.

BRASIL. Ministério da Educação. Secretaria de Educação Básica. Por uma política de valorização dos trabalhadores em educação: em cena, os funcionários de escola. Brasília: MEC, 2004. https://doi.org/10.15220/uis-unicef-cntry-brasil2012-po

BURTON, G. Teorizando o Estado e a Globalização na política e políticas educacionais. Práxis Educativa, Ponta Grossa, v. 9, n. 2, p. 315-332, 2014.

CUIABÁ. Prefeitura. Lei no 3.330, de 14 de julho de 1994. Dispõe sobre a Lei Orgânica do magistério público municipal de Cuiabá - MT. Cuiabá: Prefeitura Municipal, 1994. Disponível em: https://leismunicipais.com.br/a/mt/c/ cuiaba/lei-ordinaria/1994/333/3330/lei-ordinaria-n-33301994-dispoe-sobre-a-lei-organica-do-magisterio-publicomunicipal-de-cuiaba-mt. Acesso em: 8 dez. 2015. https://doi. org/10.5380/abclima.v14i1.38173
CUIABÁ. Prefeitura. Lei no 4.594, de 2 de julho de 2004. Dispõe sobre a lei orgânica dos profissionais da Secretaria de Educação de Cuiabá. Cuiabá: Câmara Municipal, 2004. Disponível em: https://cm-cuiaba-mt.jusbrasil.com.br/ legislacao/571721/lei-4594-04. Acesso em: 8 dez. 2015. https://doi.org/10.5216/ia.v40i2.32722

GENTILI, P.; STUBRIN, F. Igualdade, direito à educação e à cidadania: quatro evidências de uma década de conquistas democráticas. In: GENTILI, P. (org.). Política educacional, cidadania e conquistas democráticas. São Paulo: Editora Fundação Perseu Abramo, 2013. p. 15-25. https://doi. org/10.15603/2176-1043/el.v16n1p267-270

HÖFLING, E. M. Estado e políticas (públicas) sociais. Cadernos CEDES, Campinas, v. 21, n. 55, p. 30-41, 2001. https://doi.org/10.1590/s0101-32622001000300003

MAINARDES, J. Abordagem do ciclo de políticas: uma contribuição para a análise de políticas educacionais. Educação \& Sociedade, Campinas, v. 27, n. 94, p. 47-69, 2006. https://doi.org/10.1590/s0101-73302006000100003

MATO GROSSO. Lei no 5.604, de 22 de maio de 1990. Diário Oficial do Estado de Mato Grosso, Cuiabá, n. 20.436, 22 maio 1990. Disponível em: https://www.iomat. mt.gov.br/portal/visualizacoes/jornal/9947/\#/p:2/e:9947. Acesso em: 8 dez. 2015. https://doi.org/10.5327/z1677606220181307

MATO GROSSO. Lei Complementar no 50, de 1 de outubro de 1998. Dispõe sobre a Carreira dos Profissionais da Educação Básica de Mato Grosso. Cuiabá: Assembleia Legislativa, 1998. Disponível em: http://app1.sefaz.mt.gov. br/Sistema/legislacao/LeiComplEstadual.nsf/9e97251be309 35ed03256727003d2d92/178e4c93dbd56778042567c1006 edf6b?OpenDocument. Acesso em: 8 dez. 2015. https://doi. org/10.5327/z201700010017rbm

MONLEVADE, J. A. C. Funcionários das escolas públicas: educadores profissionais ou servidores descartáveis? 3. ed. Brasília: Idéa, 2001.

SHIROMA, E. O.; MORAES, M. C. M.; EVANGELISTA, O. Política educacional. 2. ed. Rio de Janeiro: DP\&A, 1999.

SINDICATO DOS TRABALHADORES NO ENSINO PÚBLICO DE MATO GROSSO. História. Cuiabá: SINTEPMT, 2016. Disponível em: http://sintep2.org.br/sintep/exibirmenu.php? menu=institucional\&id=9. Acesso em: 10 jul. 2016.

VIEIRA, S. L. Política(s) e gestão da educação básica: revisitando conceitos simples. RBPAE, Goiânia, v. 23, n. 1, p. 53-69, 2007.

Recebido em: 19/1/2018.

Aprovado em: 12/9/2019.

Publicado em: 5/11/2019.

Endereço para correspondência:

LEandro APARECIDO DE Souza

Rua Pedro Cavalo, 709 - Portal da Pérola II

16201-407, Birigui, SP, Brasil 


\section{Autores:}

Leandro Aparecido de Souza

Mestre e doutorando em Educação pela Universidade Estadual Paulista (Unesp), membro do Grupo de Pesquisa "Profissão docente: formação, identidade,

representações e saberes" (GPDFIRS), Campus de Presidente Prudente, SP, Brasil.

Técnico em Assuntos Educacionais do Instituto Federal de Educação, Ciência e

Tecnologia de São Paulo, Campus Birigui, SP, Brasil.

Orcid: https://orcid.org/0000-0002-6939-5501

E-mail: leandrosouza100@gmail.com

\section{Alberto Albuqueroue Gomes}

Doutor em Educação. Sociólogo. Professor do Programa de Pós-Graduação em

Educação da Universidade Estadual Paulista (Unesp), Líder do Grupo de Pesquisa

"Profissão docente: formação, identidade, representações e saberes" (GPDFIRS),

Campus de Presidente Prudente, SP, Brasil.

Orcid: https://orcid.org/0000-0002-2260-322X

E-mail: albertofctunesp1990@gmail.com

Endereço: Rua Roberto Simonsen, 305 - Centro Educacional

19060-900, Presidente Prudente, SP, Brasil 